\title{
Challenges in Outdoor Tourism Explorations: An Embodied Approach
}

Methodological challenges are rarely discussed in depth among outdoor adventure tourism scholars. Despite the prevailing qualitative approaches in this field, and the recognition that the fleetingness of the human experience and the non-linearity and unpredictability of the more-than-human world have the power to influence the research process, the messy, negotiated and often contested researcher's role has been less considered. In addressing this, the aim here is to critically discuss the methodological approach to explorations of the outdoor experiences through deconstructing the researcher's role. Through renderings of the existentialist propositions of being in the world and a poststructuralist philosophy of fluidity and flux, the attention is granted to embodied experiences as a way of generating knowledges. Being situated in the research setting, space is created for interrogation of the processual dimensions of commodified outdoor journeys from an emic, researcheras-tourist perspective. Research in the outdoor scenaria is by no means a linear process but rather a messy, complex and often ruptured journey, further complicated by the ethical concerns, struggles and idiosyncrasies of the researcher. I thus discuss the nuances and complexities of doing the embodied research and the haphazard ways of data collection. In shifting attention to more existential aspects of being in the outdoors through the process of post-experiential reflections, discomfort emerged as a critical quality of the outdoor experience. I thus illuminate the significance of embodied research and epiphenomenal discoveries in the production of new knowledges, to which greater attention, both in theoretical and methodological conversations, should be paid in the future.

Keywords: outdoor tourism, embodied knowledge, discomfort, embodiment, adventure

\section{Introduction}

It is ever more common that modern humans search respite in nature as compensation for their accelerated pace of life. In the contemporary, mainly western, world 'the contrast between the being of outdoors and the being of indoors could hardly be more pronounced' (Hay, 2015, p. vii). Indoor beings, aiming to compensate for their highly digitalised everyday lives, and re-establish the ontological connection with their authentic being, tend to travel to wild and nature-rich areas and thus they increasingly purchase so-called 'adventure holidays'. 
Spaces that such holidays are usually embedded in are often termed as 'liminal', for their otherworldly character, geographical remoteness and relative inaccessibility (Varley, 2011). Marine and coastal environments, for example, described as the 'penultimate frontier for tourism' (Cater \& Richardson, 2017), have become particularly attractive to people seeking novel and adventurous experiences. An increased number of tourism products have also been designed to bring the otherwise inaccessible landscapes and elusive wildlife closer to consumers. People are now enabled to go, for example, white water rafting, kayaking, scuba diving, swimming with dolphins, long-distance cycling or chasing the northern lights (Fox et al, 2014; Heimtun, 2016; Beedie, 2003).

When going on holidays, however, people take a great part of everydayness along with them, entering tourism spaces in which they dwell and move (Edensor \& Falconer, 2012). Likewise, as part of their outdoor pursuits, they are greatly 'buying' convenience. Unlike before when some of the essences of the adventure tourism product were risk, danger and uncertainty (Cater, 2006; Easto \& Warburton, 2010), adventure holidays have moved towards more immersive, slower and safer experiences in the outdoors (Farkic, Taylor \& Bellshaw, 2019; Varley \& Semple, 2015). Since the experiences sought for 'have shifted from the search for the utmost challenging and dangerous to that of safety and comfort' (Trauer, 2006, p. 185), people require services of activity providers, not only to access places but also to ensure their safe and convenient consumption. Within the context of commercial tours, activities are delivered and managed by outdoor guides that are negotiating outdoor environments, providing access to wild places, choreographing people's experiences, maintaining high levels of security and ensuring the overall hospitality and wellbeing of tourists (Farkic, 2018; Farkic \& Taylor, 2019; Varley et al, 2018; Beedie, 2003). However, despite the commodification of adventure which assumes highly managed and sanitised experiences (Beedie, 2008), entering a liminal arena in search of otherworldly landscapes and extraordinary experiences may mean stepping out of the comfort zone for some. Being in alien environs is not necessarily pleasant, and the sense of comfort and security may be reduced. Insecurities, anxieties and other unpleasant feelings and conditions, do not only apply to tourists partaking in adventure holidays, but also to researchers who set off exploring the tourism experience in the Great Outdoors.

This paper therefore aims to voice the challenges in the field work process and the knowledges that were produced through the corporeal engagement with the outdoor research setting. The overarching aim of the broader study was to phenomenologically explore how 
tourists construct their experiences in the outdoors and the ways in which hospitality works on commercial multi-day adventure holidays. To come closer to the phenomena in question, I conducted ethnographically informed research. I aimed to embody myself in a research setting and conduct fieldwork, which required my body to get attuned to a hitherto alien environment. I joined two multi-day tours on the Isle of Coll, the Inner Hebridean island off the west coast of Scotland. One of the well-established activity providers "Basking Shark Scotland" operates from both Oban on the mainland and the Isle of Coll, taking tourists to experience the extraordinary, liminoid event - close encounters with Scotland's biggest fish, basking sharks, as well as other wildlife, such as white-tailed eagles in the Sound of Mull, seals, porpoises, minke whales and numerous sea birds.

The transition from an 'indoor body' into an 'outdoor body' and into a 'researching body' was far from smooth. Adventurers are usually depicted in a rather masculinist way, as strong, capable, risk-taking individuals. Similarly, perhaps, the adventurer-researcher's role is constructed on the assumption that they are able-bodied, well-versed or experienced in a certain activity, which may not always be the case (Nairn, 1999). Moreover, amongst adventure tourism scholarship, few studies focus on the role of a researcher and the methodological challenges faced in the field (Kennedy, MacPhail \& Varley, 2018; Houge Mackenzie \& Kerr, 2013). Thus, my aim here is to extend this conversation by voicing my personal experience of the field work journey and disclose some challenges I had in simultaneously taking roles of both a tourist and a researcher. I also aim to highlight what qualities of the embodied research in the outdoors emerged from the process, juxtaposed to well-trodden ethnographic techniques normally used in tourism explorations. In doing so, I illuminate the knowledges that such an approach has produced, and the potential it has to advance outdoor tourism scholarship. Ultimately, the paper adds to the emerging methodological conversation building on pheno-existentialist philosophy and poststructuralist ideas on embodiment, through disrupting the dominant approaches to studying lived experiences in the outdoors.

\section{Dwelling and embodiment as knowing the world}

Building on early existentialist ideas, I more prominently situate the study within the philosophical discourse. My thinking about the human experience and its construction in relation to context (in this case the outdoor spaces) takes departure from existential phenomenology. Its founder Martin Heidegger (2010 [1972]), in his thesis on being and time, 
posited that 'spaces receive their essential being from particular localities, and not from space itself' (p. 332). By this he meant that human beings $d w e l l$; they co-exist in relationships that they maintain with places and others, as objects of awareness, through which they acquire meanings (1993). He also expressed the idea of directedness towards others, both humans and non-humans, through the concept he termed Mitdasein, or being-with, as an extension of Being (Dasein). The 'others' are encountered via a medium of common ground; through things that we use and the processes of exchange. Although he stressed the ontological significance of place, it was, however, untypical of him, as well as other phenomenologists, to unpack the human body in its process of being. In placing an emphasis on Dasein and dwelling as a form of being, Heidegger failed to address in more depth the role of the body in experiencing places. In confronting this omission in his work, Casey $(1997,1993)$ attempted to provide a comprehensive account of the role of place in human experience by building on the notion of dwelling. He philosophically explored the pervasiveness of place in people's everyday lives and the ways we engage with it, positing that the human body always 'takes place' in this world. He explored how Heidegger understood place and the essential part it plays in defining the life-world of experience, highlighting that the human body, perception and habitation are key aspects of being in the world. Casey (1993) suggested that 'bodies do not only perceive but know places' (p. 34, original emphasis). The experiential aspects of the place-world and questions of inhabitation of both built and wild places, positing that humans find their place within them, give them meanings and make sense of them. Spaces and places are made and remade through bodily practices, they come into presence through the experience of bodily sensations, being further heightened through affect and emotions.

The paradigmatic shift across the disciplines brought with itself new theories. Body metaphors, like the concept of embodiment, for example, suggest that the body is used as a convenient way of experiencing and thinking about the world. This is understood as an existential condition of human life and cancels any possibility of Cartesian dualism, challenging the objectification of the body and arguing for temporality and fluidity of the human experience (Swain, 2004). As Weiss and Haber (1999) remarked, 'the very notion of embodiment suggests an experience that is constantly in the making... being constituted and reconstituted from one moment to the next... changing in significance and form' (p. 43). French philosopher Michel Foucault (1979) takes the credit for conceptualising the embodiment theory. He is claimed to have greatly influenced social theory in thinking how the human body is subject to power, which in the early 1990s caught the attention of feminist 
scholarship. In attempts to understand how power works at an individual level, feminists turned to Foucault's poststructuralism and his examination of the multiple ways in which the power relations are deployed within society. They, therefore, unpack the body by questioning personal body politics and power relations, such as gender, class, race, age or sexuality, and argue for positionality as an agent in constructions of meanings. Wolf (1982) suggested that 'meanings are not imprinted into things by nature; they are developed and imposed by human beings. The ability to bestow meanings - to 'name' things, acts, and ideas - is a source of power' (p. 388).

A phenomenological approach to thinking about being in the world was later supported by poststructuralist theorists of embodiment and non-representational theorists. Hence, the original Heideggerian meaning of the notion of dwelling as being in the world has been extended to embrace both geographical and social aspects of bodily practices and relations it has with the place. Drawing on the concept of dwelling, a number of scholars have described being in the world as an embodied engagement with the environment, and accentuated everyday practices as the basis for how people dwell and construct their worlds (Ingold, 2000; Casey, 1993; Dreyfus, 1993; Macnaghten \& Urry, 2000; Thrift, 1997, 1999). For example, following a phenomenological train of thought, which holds that people are in the world in as much as they dwell in it, Ingold (2000) proposed the 'dwelling perspective' which holds that 'it is through being inhabited, rather than through assimilation to formal design specification, that the world becomes a meaningful environment for people' (p. 173). People are not only physically present in the place, they dwell in it - they are aware of it, they are sensually engaged with it through various embodied practices (Ingold, 2005, 1995). Similarly, drawing on Ingold's (1995) understanding of landscape as a milieu of embodied, quotidian dwelling, Wiley (2005) argued for 'placing the self in the body and embedding the body in landscape' (p. 240). In this vein, perceptions, memories and bodily movements are understood as being both in and of landscape and gather landscape together as a lived milieu. Thrift's $(2004,1999,1997)$ work on the body and nature through his non-representational theory provided valuable insights. He not only suggested why contemporary people may seek more embodied nature-based activities but also offered insights into understanding how the human body engages with the natural world. The human body and other natural objects do not stand as separable entities but exist in assemblages, multiplicities and co-evolving 'blocks of becoming' (Thrift, 2004). Thus, the landscape might best be described in terms of the entwined materialities and sensibilities with which humans act, move and sense the world. Kinetic empathy may stimulate and engender the cultural turn to the affective and sensuous 
(Thrift, 2008). There is also much to thank cultural geographers for their theorising of the construction of spaces through the concept of performativity as a form of dwelling. For example, Edensor (2000) analysed a number of embodied tourist performances (walking, gazing and photographing in particular) that play an important role in constructing tourist spaces. In his account, he decentred visual sense and shed light on the importance of other senses, proposing that via immersed tourism practices tourism spaces are enacted and performed. Edensor (2006, 2000a, 2000b) suggested that in the process of embodiment, the materiality of places and spaces should not be neglected. Spatial affordances, as he termed them, greatly constrain and enable a range of actions; 'the surfaces, textures, atmospheres, smells, sounds, contours, gradients, and pathways of places encourage humans to follow particular courses of action, producing an everyday practical orientation dependent upon a multisensory apprehension of place and space' (Edensor, 2006, p. 30). Humberstone (2015, 2013) takes the credit for elaborating the embodiment theory in the context of nature-based physical culture in focusing on the ways in which humans learn through their bodies. Further understandings of the relationships between body, emotions and the elements in relation to adventurous activities are the focus of her work, which advances the knowledge on sensorial experiences of participants in outdoor activities.

\section{Embodied tourism experience}

For a long time, little attention was paid to phenomenological explorations of tourists as individual, 'corporeal subjects' that know the world and gain experiences through their bodies. The body has become of great interest to tourism scholarship since Veijola and Jokinen (1994) and Johnston (2001) challenged the disembodied, hegemonic and masculinist research in tourism. Desmond (1999) proposed that 'we must have a more fully embodied concept of the tourist, expanding the notion of the 'tourist gaze' to include other embodied aspects of experience (movement, sound, touch and so forth), both in the physical and imaginary realms' (p. xxi). Since then, the human body and the senses have been significantly considered within tourism theory.

Although Heidegger's concept of dwelling was not initially conceived to embrace tourist practices and mobilities, some authors have used this notion to describe embodiment in the world through tourism (Varley, Carnicelli and Farkic, 2018). For example, Obrador Pons (2003) articulated tourists' dwelling as their engagement with and involvement in a physical environment as a way of creating knowledge. Recounting Heidegger's ideas, he made a point 
in suggesting that physical presence in a certain space is not sufficient, but one needs to be bodily immersed in it, in order to gain experience. A place like a beach for example 'needs to be apprehended as a place where the body lives, experiments and desires, a place of embodied utopias and nondiscursive pleasures' (p. 55). He drew attention to numerous nonvisual sensations that influence the tourism experience, such as 'the feeling of the sun caressing the skin, the sensual movement of the naked body into the seawater and the unpleasant infiltration of sand into body orifices' (2007: 134).

Engagement of and experiencing through the body has also been acknowledged by adventure tourism scholars, positing that the body is a medium for negotiation of experiences while undertaking adventurous activities. Adventure tourism has been traditionally claimed to provide challenging activities in natural environs that test the human body and trigger intensive experiences. It seems more obvious that embodied experiences are easier to capture in cases of more intense activities, where the body is challenged and tested (Cater \& Cloke, 2007; Cloke \& Perkins, 1998). Cater (2006) explained that adventure tourism is 'clearly about active participation with the body' (p. 66). Illustration of this can be found in Fox et al.'s (2014) example of cycling, where they claim that 'part of the attraction to cycling begins with the bodily experience of being on, melting into, and flowing with the bicycle as it moves through spacetime: that is, the embodied experience of cycling (p. 74).

The body, understood as a medium through which experiences and knowledges are created, has obviously received a more pronounced recognition across disciplines in the past few decades, which laid the foundations for the further phenomenological understanding of lived experiences and embodied knowledges in the context of tourism in the outdoors. To unpack the body as the site of knowing, I, therefore, build on early pheno-existentialist ideas on being in the world, and complement them with poststructuralist propositions of dwelling, embodiment and multisensory engagement in outdoor tourism spaces. The ensuing section positions the body as a credible instrument for research.

\section{Body as an epistemic medium}

Tourism researchers have taken an increased interest in understanding people's experiences and social dynamics during commercial journeys in wild nature (Cater \& Richardson, 2017; Carnicelli, 2013; Varley, 2011; Curtin, 2010; Scarles, 2009). To embody themselves into a research setting and gain insights into human interactions, they take an ethnographic approach, as it allows them 'to describe the lives of people other than ourselves, with an 
accuracy and sensitivity honed by detailed observation and prolonged first-hand experience' (Ingold, 2008, p. 69). However, ethnography is not always characterised by long-term engagement with other people's lives, as in traditional anthropological studies (Malinowski, 1922; Marcus, 1998). Rather, as Pink (2013) explains, it involves intensive excursions into their lives with the aim of creating context through which to explore what is of the researcher's interest. In the short-term research encounter, the intensity of interaction with participants is pronounced, through which knowledge is generated (Pink \& Morgan, 2013). To that end, spaces of outdoor adventure lend themselves well to ethnographic practice (Cater \& Cloke, 2007). Although it has gained momentum in social sciences, in outdoor adventure tourism it has only recently started to be increasingly utilised (Kennedy et al, 2018; Humberstone, 2015; Houge Mackenzie, 2013; Carnicelli-Filho, 2013; Rantala, 2011; Rantala et al., 2011; Kerr \& Houge Mackenzie, 2012; Sharpe, 2005; Beedie \& Hudson, 2003).

If we want to think about elusive social realities, however, we need 'to teach ourselves to think, to practice, to relate, and to know in new ways' (Law, 2004, p. 2). With the critical turn in tourism, the 'orthodox methodologies' (Wilson \& Hollinshead, 2015) were disregarded and more disruptive approaches have been adopted. Researchers have been increasingly encouraged to embrace unusual and innovative methods in order to advance qualitative inquiry in tourism studies (Buda, d'Hauteserre \& Johnston, 2014; Bianchi, 2009; Denzin \& Lincoln, 2009; Airey \& Tribe, 2007; Ateljevic et al, 2005; Botterill, 2001). Therefore, more humanistic approaches have been adopted, which 'embody the researcher and humanise the research process' (Wilson \& Hollinshead, 2015, p. 30). Rethinking tourism as an embodied experience and the tourist as an affective, embodied subject, has largely helped stimulate their thinking as contextual, fluid and dynamic, created as a result of embodied, affective and performative practices.

In tourism research, the attention has been greatly shifted to the agency of the individual, as a way of deconstructing and deepening understanding of the processes and contexts within which the meanings of experiences emerge. However, being a social scientist is a messy condition. We bring into research our idiosyncrasies and subjectivities, which have a major influence on the research process (Bourke, 2014; Pritchard \& Morgan, 2011; Ateljevic et al., 2005). Feminist scholars have long disrupted 'the idealised image of the lone, ungendered, unbiased researcher, going into the field like a neutral, empty vessel simply waiting to be filled with data' (Billo \& Hiemstra, 2013, p. 321). It is 'reasonable to expect that the researcher's beliefs, political stance, cultural background (gender, race, class, socio-economic 
status, educational background) are important variables that may affect the research process' (Bourke, 2014, p. 2).

The researcher's positionality therefore greatly matters. Hall (1990) emphasised that 'there is no enunciation without positionality. You have to position yourself somewhere in order to say anything at all' (p. 18). At the time of writing, I identify as a middle-class female of Serbian background, currently in my late thirties. Prior to setting off to do the field research, I had possessed the pre-understanding of what Heidegger (1993) termed fore-structures, that is, pre-knowledge of concepts that influence our understanding of the world. For example, in my explorations of human experiences and social dynamics in the outdoors, I had pre-knowledge of relevant concepts such as tourism, adventure, embodiment, lived experiences or guiding. It was impossible to bracket what I had previously known, and what I strived to find out, and enter the field entirely tabula rasa. Yet I was an inexperienced researcher. Having a background in the positivist research paradigm, doing research in a foreign land, and in a different language, all brought tensions and insecurities both prior to and during the research process. Things were further complicated by having to conduct it in a non-native language. I had to acquire new terminology and become comfortable with it, as I was what Stebbins (1998) termed an 'ethnic outsider'. I also found it difficult to switch between my insideroutsider roles (Kennedy, MacPhail \& Varley, 2018) - being me and me being a researcher, doing things for the purpose of my research I would not have done otherwise (for example chatting to the skipper in the cockpit while getting seasick).

However, writing about knowing through our bodily responses, that is, on the notions of haptic knowledge, of proprioception, is scant among adventure tourism scholarship. Crang (2003) asserted that 'the body quite often ends up as providing a sort of inescapable positioning of the researcher - through race, dis-ability or gender - but less often is the body the instrument of research'. In confronting this, I attempted to sense the field by way of my body and became an 'observant participant' (Walsh, 2009). I was doing what humans do on holidays anyway - chatting, laughing, cooking, walking, snorkelling, eating, taking photos. This approach enabled me to corporeally enter various social and physical spaces, more easily take part in activities and become more personal with others (Dowler, 2001).

I utilised a patchwork of ethnographic methods to complement, extend or replace one another, depending on the given circumstances. To document the experiences, however, I kept a field diary, eventually assembling a large amount of textual material. Initially, such knowledge was heterogeneous, disconnected and disorganised. Allowing time for passiveness 
and idleness during and post-fieldwork, some themes crystalized, assembled, and became more potent in generating theory than others. I came to realise that I was paying considerable attention to my bodily reactions and emotional journeys whilst doing the research that equally populated my diary pages alongside observations of the reactions and experiences of others. In the coding process I initially grouped the data into broader themes. Rather frequently, I noted the moments of stress, fear, hesitancies, anxiety, awkwardness or exhaustion, to which I eventually assigned a common denominator and termed them collectively as discomfort. Across the following sections, through the presentation of diary excerpts, I disclose these moments and subsequently discuss the knowledges and opportunities that emerged from them.

\section{Voicing moments of discomfort}

The first tensions about conducting fieldwork arose alongside methodological considerations. I was certain about doing the ethnographically informed research, and yet I had no previous experience in being away for days, researching. I also realised that there is no formula for how to do the research, as it is by no means a straightforward enterprise. I recall the feeling of a lack of confidence before I set off on my first tour. Being introduced as a researcher, although I was also a tourist who purchased the tour, I could not help feeling like an intruder, as an embodied subject observing the interactions of others. I had ethical concerns in relation to formalising the encounters and declaring myself as a researcher and explaining my intentions. I faced my first challenge when I was about to hand out consent forms at the start of the first tour, which is something that is supposedly a common practice while commencing a field work. Nonetheless, negotiation of the time and space to give out consent forms was somewhat problematic:

I knew I had to find the right moment to tell the group that I was the one doing my research, briefly explain what it was about and kindly ask them to sign the consent forms. I was a bit nervous as the time and place didn't really look right (actually, it looked ideal - white beaches all around and infinity views, far away from everything and everyone!). I waved at the group and they soon gathered around me. I introduced myself again and said that I was in fact on 'busman's holiday'. Having explained that I'd need their signed consent to be able to proceed with the research, they all agreed and nodded. While I was reaching out to grab the forms from the bag, someone asked: "Do we need to sign them NOW?!", moving his eyes like he was pointing to the 
weather conditions. It was dreary and it was blowing a hooley there at the cliff and it was of course absurd to do it right there and just then. Someone else was witty and said he'd sign the form and I could wait for the paper at the other side of the beach, suggesting the wind would sweep it off his hands. Everyone laughed and simply walked away, scattering across the beach again as if nothing happened. I looked at the folder with the pile of unsigned forms, turned around as if I needed to confirm the poor weather conditions and thought to myself: "Yeah, why not take them to the boat tomorrow?".

I always thought handing out consent forms was out of place - whilst sitting in the bunkhouse, standing at the beach of Coll being exposed to the sweeping wind, or sailing on the rib rocking on the choppy sea. It was never a good moment for it, as depicted below:

We were on the way back to Oban, the tour was nearing its end. I still needed to give out the consent forms to the guides and John and Y.G. so I asked if it would be okay to sign just then. I gave them the papers, and they started reading through the text. I knew it wasn't the right moment, the rain was hammering, the rib was at its maximum speed and the papers were soaking and constantly folding.

Due to its instability and unpredictability, the weather is usually a major challenge in outdoor tourism. Its materialities are critical to framing the actions throughout the trips (Rantala et al., 2011). Therefore, anticipation and coping with the weather was crucial throughout all stages of the trips: from sailing out on a rib, to doing the activities, to doing the research. There were episodes of very poor weather conditions, during which it seemed that nothing was going on for hours, we did not spot any sharks nor swam with them, we were only sitting at the deck, very obviously disconnected from one another, just going with the flow and bearing with the conditions. And yet, these experiences were memorised and later recorded in my diary:

For the next couple of hours, we were just sailing. Our energy dropped and everyone looked miserable and soaked to the bones. Some of us took out a packed lunch and were eating with wet hands. Matt's bread was soaking and falling apart. I was completely unaware of the time, all I could see around me was water, water, endless water. Everyone was silent. I was eating my tuna sandwich, completely hypnotised by the movements of the waves all around me. I was hallucinating I was seeing whales, but these were just the waves, appearing, disappearing, changing their shapes. This lasted for a while. I couldn't take it any longer, I felt exhausted and I wanted to go back and feel the solid ground under my feet. 
In situations like these, I simply had to 'work with' the weather and allow for more flexibility in managing my research process, putting off the conversations or notetaking or any other research activity. I was feeling seasick and mentally exhausted, like everyone else was, yet in these moments the research, in its conventional shape and form, was hardly possible.

I took my motion sickness pill, it turned out that it was a wise decision since other people on the boat were getting sick on the choppy sea and kept throwing up. Emily didn't even want to change into a wetsuit on the second day. She said she saw the sharks and that was enough for her. Y.G. was occasionally throwing up from the boat, bending over the edge and splashing her face. Vincent had his antacid pills which he was offering to everyone. I couldn't stand on my feet, I sat down and gripped the rail. Most of the group were pale in the face and impatient to jump into the water.

Getting attuned to the immediate environment assumed our gradual familiarisation with the boat, as a space that was shared most often, knowing how it moves, how it is operated, where to sit in order to avoid the splashing of the waves, or how to get in and out of it. We spent most of our time sailing on the rough sea, and it seemed like no one could find their cosy, personal place:

The boat seemed very uncomfortable in the beginning, and whatever corner I found myself in, I felt I was always in someone's way. It was wet, and small and claustrophobic and our stuff was all around it.

It was interesting to observe how our relationship with the vessel developed over time - from complete strangeness to almost complete familiarity. Technologies, such as boats, are described as spaces through which individual and inter-subjective practices may be extended, making the encounters possible (Crouch \& Desforges, 2003). There was a lot of social activity going on on the boat: watching wildlife, changing into wetsuits/dry clothes, zooplankton sampling, conversing, eating, or jumping into the water after sharks. Humberstone (2013) suggested that in these situations 'the participant loses track of time and becomes one with their equipment, the elements and the natural environment' (p. 568). At times, overwhelmed and engrossed in the activity, taking notes was not my priority. Very little time and space was allowed for it, thus I mostly relied on taking photos or making mental notes. I first needed to make sure that I was comfortable on the boat and in the water, that I was well and rested and present in the moment. 
Personal belongings, too, played a significant role in the process of familiarisation, or 'becoming comfortable' (Varley \& Semple, 2015) with the space we occupied. For example, while standing at the deck of the rib, pressing my hands hard against the cup of tea to warm up, I was watching others, or doing the participant observation, appearing between the cairns and playing with seals just in front of the boat. Unpleasant bodily sensations overwhelmed me after several hours of being in the wetsuit, buffeted by the winds, being seasick and learning how to snorkel in cold waters. I had changed into dry clothes but was constantly shaking in the cold weather. In my later reflections on this event, I noted:

Now I was properly cold. I started shivering and didn't dare to go further. I felt my skin was all wrinkly and salty and the wetsuit carved a new texture on its surface. Thousands of midges were hovering above us in clouds. I decided to go back to the boat, to escape the midges, to get rid of the wetsuit, to warm up and forget about this nonsense. I just wanted to be wrapped up in a blanket, that's all I wanted.

Instead of noting down my observations, what I initially intended to do, I kept standing at the deck, wrapped up in a towel and waiting for my body to relax from a spasm. My gaze into the distance was interrupted by Vincent's spontaneous move. He swiftly put his hat on my head, saying: "You'll catch a cold, your hair is completely wet!". Having his hat on, and not feeling the cooling breeze anymore, I immediately felt tingling sensations all over my body. The blood was returning into my head and I could feel the warmth around my neck.

Adventurous activities rarely go without a certain amount of hardships and unpleasantness (Beard et al, 2012), even on commercial outdoor tours where comfort and safety are a priori paid for. Clothing and other specialist equipment, as well as its efficient use and briefing on the kit (in this case wetsuits, fins, masks and snorkels) is crucial in guided outdoor adventures (Beedie \& Hudson, 2003). Familiarisation with equipment is important as it becomes part of people's bodies, through which they negotiate environment (Merchant, 2011). When it produces confusion, it detaches the body from the environment and the experience of undertaking activities is diminished. Small omissions on behalf of the activity provider, such as providing inappropriate gear, can affect the overall experience of clients. There were many occasions when our bodies suffered due to the influence of inclement nature and the unfamiliarity with the environment that was not our normal habitat. For example, on the first tour I was accidentally given a larger size of wetsuit, which made my body less capable of doing the research in/under water. I wrote about this particular experience: 
Trying to snorkel in the cold water I could entirely identify with Cain's experience, one of the Knausgaard's characters in his novel "A time for everything", when he attempted to run across the fields and ran out of breath. My throat was constricting and my lungs began to get all knotted after only a few metres and I felt as if I was breathing through a straw. The cold water was flushing into my wetsuit, straight down my spine. I won't last long, was the only thought I had as I was trying to make a move towards the guide who was floating with ease in the distance. My fingers and toes went numb after a few moments, the blood had already retreated from my extremities. I then forced my legs to make a quick move forward, but the more I tried, the further from the guide I seemed to be. I then tried to use my hands and make wide strokes, but instead, my hands were flapping back and forth in the water and I think I didn't make a single breathe while I was trying to pull myself together. When in despair I raised my hand to attract attention, the air flooded back into my lungs and I all of a sudden felt at ease. I had no energy to wobble my legs, nor my arms, and I involuntarily relaxed. To my great surprise, I realised I was floating in my neoprene suit. In the contact with freezing cold water I simply sank into complete oblivion and fought for bare life.

It was incredibly difficult, at times impossible, to collect data, particularly in the moments of panic, or whilst sailing in a small dinghy on the choppy sea, standing at the deck tightly gripping the rail whilst being splashed by giant waves, soaking in the rain for many hours during the day, getting seasick, shivering in a wetsuit, or being underwater. The body would simply 'get in the way' of enjoyment in activities, constrain and define its movement through spaces (Markwell, 2001). It was difficult for me to learn the technical skills of snorkelling, and at the same time be alert to what was going on - to focus on conversations, events and social interactions, as well as manage my own emotions and observe the behaviour of others. However, through the states of discomfort, which occurred rather frequently, some lessons have been learnt.

\section{Lessons learnt}

Embodied fieldwork and the process of reflexivity helped me understand the complexities and nuances of research in the outdoors, and the ways in which new knowledge was produced (Billo \& Hiemstra, 2013; England, 1994; Kobayashi, 1994). To become both a tourist and a researcher, it was necessary to accommodate myself to 'the affordances that 
were dwelt within and passed through, and out of these adaptions sensuous apprehensions and practical epistemologies emerged [sic]' (Edensor 2006, pp. 31-32). Due to the interplay of shifting sensualities and emotions in the field encounter, I largely put an emphasis on the body as an instrument of research. Although adventurers are normally depicted as strong, confident, courageous and daring, an adventurer-researcher has by all means a challenging task - to simultaneously undertake activities, manage emotions, control shifting mental states, and collect data, all within a very short timeframe. I was frequently switching between my various roles, learning from attachment to and detachment from the research setting, active participation in activities, shifting mental states, negotiations, observations, conversations and reflections. In the research process my idiosyncrasies and subjectivities came to the surface and influenced the way I was doing the research, even though I was part of the commodified, convenient and to an extent safe environment. Nonetheless, I learned what it felt like to be physically and mentally exhausted from undertaking the activities, accompanied by adrenaline rush, exaltations, hesitations and anxieties, while at the same time making sure I was maintaining the focus on my research. This, however, produced new knowledges, which led me to think of the existential aspects of being in wild nature, the creation of a sense of security and psychological wellbeing in the outdoors.

\section{Benefits of the intensive encounter}

Intensive short-term ethnographically informed research may be greatly insightful. I learnt how the anticipation, reading and modification of lived experience was influenced by entering various social and physical spaces, and how they were affected by the more-thanhuman world. Participation in outdoor activities presupposes attunement, where both the researcher's and participants' movements are grounded in shared circumstances (Lee \& Ingold, 2006). It is suggested that 'both researcher and respondent become vulnerable as they expose their selves; each finding solace within the visual as they come together in sharing the intensities of emotions, somatic knowledges and haptic spaces of encounter' (Pink, 2010, p. 923). Senses, emotions and affects are relational and emerge from the space between sensing and sensed, that is, 'to sense is always to sense with' (Anderson \& Wylie, 2009, p. 326). However, sensing-with is not always reduced to a single human being. It is 'an aesthetic sensibility, a sensation of being at one with the immediate environment that might include the presence of others, together with a combination of memory and anticipation of specific events' (Bissell, 2008, p. 1700). Such 'intersubjective exchange materialises as shared 
corporeal expression as the immanence of encounter opens intimacies of the self' (Pink, 2010, p. 923).

In particular, the act of sharing (spaces, time or things) as a manifestation of Midasein, that is the ontological 'withness' proposed by Heidegger (2010[1972]), is a prerequisite for 'communitesque' (Lugosi, 2008) encounters in commercial tourism settings. In either sharing the confined spaces of the boat, bad weather, moments of fear and exhaustion, both materiality and sociality of the outdoor experience were bound together. Through the consumption of various 'scapes', we became attuned to the ever-changing and unpredictable nature of the outdoor environment. Furthermore, in sharing the confined space of the boat most of the days, our personal spaces seemed to have collapsed, which allowed for closer insights into one another's bodily reactions and mental states, which in 'normal' circumstances would most likely not be the case. Furthermore, the imagined void I felt between myself and others was colonised by our interactions, and spaces were created for getting more personal with others. I began to realise the significance of the space in-between and I soon became more comfortable with myself, as a participant in activities and as a researcher. Enforced proximity triggered our more frequent communication and prompted reflections and stories surrounding the towel, pills, flip flops, hats, flapjack, GoPro screws and all the things lent and borrowed during the trips. The temporary sharing of space and time not only broke down formal barriers and enabled me not only to collect richer data, but also to create intimacy and fellowship and build trust with others (Still, 2011). The feeling of belonging to a small group is considered to be one of people's existential needs, which may be fulfilled through sharing adventurous spaces loaded with diverse, often contrasting, emotions.

\section{Agency of the more-than-human world}

The 'social' is a more heterogeneous mix of not only humans, but also other-than-human 'things' (Latour, 2005). Being embodied in the research setting, it was necessary to allow my body to sense the hitherto alien environment and learn its rhythms, taking into account various non-human actants as agents in constructing the outdoor experience, as well as in the process of collecting data. Outdoor spaces are not fixed, but rather a continual process of interactions between materialities and immaterialities within them, of which humans are only a part and do not control. Materiality is multiple: it involves natural objects, phenomena and processes that are beyond human control, defined in terms of movement and process rather 
than stasis. Outdoor and social spaces were thus negotiated through the act of sharing of both material and immaterial aspects of a tourist habitus. Edensor (2006) termed these elements 'spatial and material affordances' through which people explore, engage, and understand their experience, and which have power and agency in constraining or enabling their practices, and more or less influence the intensity of the lived experience as well as the research process.

Perceiving, sensing and becoming attuned to natural rhythms was highly relational insofar as these materialities/mobilities are the very sparks which ignite passages of perception and sensation, and concordances or dissonances, of bodies and things' (Anderson \& Wylie, 2009, p. 326). The weather conditions influence the colouring and shading of the surrounding landscapes, creating and providing a unique backdrop for outdoor activities. Rare and unusual natural spectacles are particularly appreciated by tourists as they are perceived as more affective encounters (Edensor, 2006). Rather unsurprisingly, however, bad weather can obstruct activities and influence people's psychological wellbeing. I felt how the materialities of the weather had a forceful influence not only on my sense of comfort but also on the process of my research. Being outdoors and doing the activities, most of the time exposed to strong winds and rain, I was free of audio recorder, pen and paper, as technologies that would normally assume research. This, however, led me to rely on my body as the only available instrument of research in most situations.

\section{Alternative data collection methods}

As previously mentioned, I found the ethnographic approach and participation in guided tours an appropriate way to gain embodied, situational, and practice-related knowledge around guiding and hospitality in the outdoor scenarios. However, I did not have any a priori defined methods nor a rigid field research design. Rather, I had a loose framework and kept my mind open and alert to various 'imponderabilia' (Malinowski, 1922) throughout the research process. Chang (2008) claimed that 'the flexibility of research design should not be misconstrued as a lack of diligence or indecisiveness in planning' (p. 67), and therefore a less structured approach, although much more challenging, allowed for generating richer and more nuanced data.

I realised that much could be gained through spontaneous, entirely unstructured, leisurely conversations, free from disturbances and anxieties that could have arisen from the formalities of the interview process. I thus privileged conversations on the move, which 
allowed myself, both as a researcher and informant, to be more exposed to the multisensorial stimulation by being embodied in the surrounding environment (Adams \& Guy, 2007). This was particularly valuable as it allowed the context, both social and environmental, to frame the conversations (Evans \& Jones, 2011). This way, any conversation we had during tours was not interrupted by formalities, allowing for naturally flowing, unconstrained, insightful conversations. Such impromptu conversations occurred, for example, standing in the rain in the pier, shivering at the deck or struggling to learn how to snorkel. Each datum collected during the research encounter inevitably had an agency in layering, shaping and constructing the knowledge around the lived experiences.

Most of the time, however, I had to rely solely on my memory, as a method for 'storing' and 'processing' the data. I was mindful of other people's conversations as invaluable empirical data. I found it particularly difficult to memorise conversations and reproduce them afterwards as accurately as possible. For this reason, whenever possible I was turning to my phone and writing notes in the form of direct quotes, or noting snippets while chatting to others. In cultural studies, memory is a key method through which lived experiences are explored, usually through memory work. However, its utilisation as a method of generating and eliciting data, which is the case in this study, this may appear problematic as the credibility of the method might be questioned. For this reason, Pickering (2008) suggested that elicited memories should be triangulated with other documentary evidence or narrative data, in order to achieve a more methodologically sound account. Writing my field diary, based on memories, was thus supported by a large number of brief notes, various memorabilia, images, sketches, text messages, emails or videos, that not only helped me in the reconstruction of events but also serve as their evidence. Eventually, an account loaded with descriptions of the bodily sensations and moments of discomfort emerged.

\section{From voicing emotions to epihenomenal discoveries}

I also learned much from the moments when methods did not quite work and the periods in which no data were collected. There was a number of situations, some of which I illustrated earlier through the diary excerpts, in which standard ethnographic methods were of no use. No usual research technologies assisted me in this process, and the only instrument for collecting data was my body. Therefore, to aid this, post hoc expressive writing of a field diary with sincere, deep, emotion-rich accounts turned out to be a valuable resource in my reflecting on the past events, from which new knowledges emerged. 
Various affective and emotional encounters provided me with 'analytical clues' (Davies, 2010; Koning and Ooi, 2013) and offered an opportunity to enrich my understanding of the field as well as my role in the production of knowledge. This process is regarded as highly emotional, transformative and revelatory (Moriarty, 2016). However, Punch (2012) argued that voicing emotions and personal challenges into discussions of the research process is still not fully accepted as a scholarly endeavour. Researchers tend to silence emotions either not to reveal their weakness or to achieve objectivity and get closer to the 'truth' (Widdowfield, 2000). They still struggle with 'transparent reflexivity' articulated through more explicit writing of their accounts. Arguably however, acknowledging, writing and speaking about emotional experiences during the field research can add considerable value to the research, both during its process and its outcomes. The field diary may thus greatly assist in reflecting on hidden struggles in the production of knowledge, reveal not so obvious aspects of the experience and reveal some of its aspects that might not have been considered otherwise (Corbetta, 2003). For example, moments of hesitancies, anxieties, pleasures, security, belonging or not belonging, were later considered in relation to humans' existential being; through our striving for ontological security and existential comfort whilst journeying in the outdoors (Farkic, 2018; Varley et al., 2018).

\section{Conclusions}

This paper sought to discuss the methodological journey of the neophyte snorkeler who found herself in the 'liminal playground' to do research (Gyimothy \& Mykletun, 2004). However, doing the research as well as being a tourist on the outdoor tours was far from an easy task. Stepping out of the comfort zone carried certain constraints due to embodied reactions to the immediate, alien and at times harsh environment. There was a series of uncomfortable occurrences at work. I therefore aimed to voice the moments of discomfort to show that doing research in the outdoors, particularly on commercial tours on which affordances are a priori paid for and risks and thrills are adequately managed, is certainly not devoid of potential subjective in-situ constraints. They may diminish the overall outdoor experience and may in many ways constrain the research process. However, this has brought invaluable insights which may in their own right contribute to the extant tourism literature.

There is nothing new in this paper disrupting the predominant structuralist approaches to studies of the tourism experience. I aimed to deconstruct the experience and to more prominently acknowledge the inseparable relationship of the body and space, which further 
led into discussions of the body as a medium through which experiences are created. In so doing, however, I invited existential philosophers into the conversation. I privileged works by the early phenomenologists. In particular, I saw strength in the ontology of Martin Heidegger, and his proposition of the existentialist concepts of being and dwelling. To supplement this, I introduced the poststructuralist theory of embodiment, which suggests that embodied approaches may provide more nuanced, contextualised knowledges around interactions and negotiations of subjective experiences in outdoor tourism explorations.

Much can be gained from active participation in activities and observing how the body dwells and listening what it has to say. This is a kinetic and sensual process which is in most cases unpredictable and uncontrollable yet has the huge potential to disrupt the conventional ways of knowing and produce new knowledges. In moving away from thinking of the body as something bounded, fixed and finite (as boundedness makes us think anthropocentrically), I argued for the agency of the individual, however in relation to the social. In so doing, I disrupted existing conceptualisations of, for example, the researcher-adventurer who is strong, masculine and able-bodied and whose feelings and emotions are in most cases removed from discussions in the context of doing research in the outdoors. Thus, through exploring a more affective and emotional response to being on outdoor tours, I made sense of the relational nature in meaning-making processes and co-production of experiences and knowledge. I embraced the rhizomatic, relational, more than human thinking which made more space for alternative ontologies in explorations of adventure tourism.

The paper further adds to the debate around more flexible and less rigid qualitative methodologies in tourism explorations. To that end, embodied research approaches may deepen our understanding of tourist experiences and provide nuanced knowledges of the consumption and production of tourist spaces, particularly in the context of outdoor adventure. Pink (2015) suggested that more sensory approaches may bring 'to the fore the tacit, normally unspoken (about) ways of knowing and doing that are part of our everyday life. These activities underpin much of what we do and means to us; they are often mundane and feel so 'normal' to our participants that they might not even think that they are worth mentioning, but they are also part of the way we feel and sense our futures' (p. 193). Subsequent reflections on bodily reactions provided me with more nuanced, contextualised knowledges around interactions and negotiations of the lived experience in the outdoors. In summary, the paper disrupts the dominant, masculinist ways of doing research in the field of adventure tourism studies. Firstly, it deconstructs the researcher's role and voices the 
experiences less spoken of. Secondly, it argues for the credibility of idiographic studies, particularly from the researcher-as-tourist perspective. Thirdly, it suggests that autoethnographic, immersive, and reflective approaches have the potential to convey idiosyncrasies and reveal hidden aspects of the experience which can make meaningful contributions to theory. In this particular study, the sense of discomfort came out as an epiphenomenon, and a critical quality of the whole research process, as well as the overall outdoor experience. This finding may extend the scholarship concerned with tourist experiences in nature-based tourism and extend the debate on the notion of (dis)comfort on outdoor guided tours and its management. Ultimately, the study aims to encourage philosophical underpinnings of and pheno-existentialist approaches to adventure tourism research through partly addressing the famous Heidegger's question - what it means to be (a human, a researcher, a tourist).

\section{References}

Adams, M. \& Guy, S. (2007). Senses and the city, The senses and society, 2(2), 133-136.

Anderson, B. \& Wylie, J. (2009). On geography and materiality, Environment and Planning A, 41(2), pp. 318-335.

Ateljevic, I., Harris, C., Wilson, E. \& Collins, F.L. (2005). Getting 'entangled: Reflexivity and the 'critical turn' in tourism studies', Tourism Recreation Research, 30(2), 9-21.

Beard, C., Swarbrooke, J., Leckie, S., \& Pomfret, G. (2012). Adventure tourism. Routledge.

Beedie, P. (2008). Adventure tourism as a 'new frontier' in leisure. World Leisure Journal, 50(3), 173-183.

Beedie, P., \& Hudson, S. (2003). Emergence of mountain-based adventure tourism. Annals of Tourism Research, 30(3), 625-643.

Bianchi, R. V. (2009). The 'critical turn' in tourism studies: A radical critique. Tourism Geographies, 11(4), 484-504.

Billo, E., \& Hiemstra, N. (2013). Mediating messiness: expanding ideas of flexibility, reflexivity, and embodiment in fieldwork. Gender, Place \& Culture, 20(3), 313-328.

Bissell, D. (2008). Comfortable bodies: sedentary affects, Environment and Planning A, 40(7), pp. 1697-1712. 
Botterill, D. (2001). The epistemology of a set of tourism studies. Leisure Studies, 20(3), 199-214.

Bourke, B. (2014). Positionality: Reflecting on the research process, The Qualitative Report, 19(33), 1-9.

Buda, D. M., d'Hauteserre, A. M., \& Johnston, L. (2014). Feeling and tourism studies. Annals of Tourism Research, 46, 102-114.

Carnicelli-Filho, S. (2013). The emotional life of adventure guides. Annals of Tourism Research, 43, 192-209.

Casey, E. (1997). Smooth spaces and rough-edged places: The hidden history of place, The Review of Metaphysics, 267-296.

Casey, E. (1993). Getting Back into Place: Toward a Renewed Understanding of the PlaceWorld. Indiana University Press.

Cater, C. I., \& Richardson, S. (2017). Marine and Coastal Tourism. In Marine and Coastal Resource Management: Principles and Practice (p. 18). Taylor \& Francis.

Cater, C. \& Cloke, P. (2007). Bodies in action, Anthropology Today, 23(6), 13-16.

Cater, C. (2006). Playing with risk? Participant perceptions of risk and management implications in adventure tourism, Tourism Management, 27(2), 317-325.

Cloke, P. \& Perkins, H.C. (1998). Cracking the canyon with the awesome foursome: representations of adventure tourism in New Zealand, Environment and Planning D: Society and Space, 16(2), 185-218.

Corbetta, P. (2003) Social Research. Theory, Methods and Techniques. London: Sage.

Crang, M. (2003). Qualitative methods: touchy, feely, look-see?. Progress in Human Geography, 27(4), 494-504.

Crouch, D., \& Desforges, L. (2003). The sensuous in the tourist encounter: Introduction: The power of the body in tourist studies. Tourist Studies, 3(1), 5-22.

Curtin, S. (2010). Managing the wildlife tourism experience: The importance of tour leaders. International Journal of Tourism Research, 12(3), 219-236.

Davies, J. (2010) Introduction: emotions in the field, in Davies, J. and Spencer, D. (eds.), Emotions in the Field: The Psychology and Anthropology of Fieldwork Experience, Stanford University Press, Stanford, CA, pp. 1-31.

Desmond, J. (1999). Staging tourism: Bodies on display from Waikiki to Sea World. University of Chicago Press.

Dimmock, K. and Wilson, E. (2011). Take a deep breath: how recreational scuba divers negotiate in-water constraints', Leisure/Loisir, 35(3), pp. 283-297. 
Dimmock, K. and Wilson, E. (2009). Risking comfort? The impact of in-water constraints on recreational scuba diving. Annals of Leisure Research, 12(2), pp.173-194.

Dimmock, K. (2009). Finding comfort in adventure: Experiences of recreational scuba divers, Leisure Studies, 28(3), pp. 279-295.

Dowler, L. (2001). The four-square laundry: Participant observation in a war zone, Geographical Review, 91(1-2), 414-422.

Dreyfus, H.L. (1993). Heidegger's critique of the Husserl/Searle account of intentionality, Social Research, pp. 17-38.

Edensor, T., \& Falconer, E. (2012). Sensuous geographies of tourism. The Routledge handbook of tourism geographies, 74-81.

Edensor, T. (2006). Sensing tourist spaces. In Claudio Minca and Tim Oakes (Eds). Travels in paradox: Remapping tourism. Rowman \& Littlefield Publishers. pp. 23-45.

Edensor, T. (2000a). Staging tourism: Tourists as performers, Annals of Tourism Research, 27(2), pp. 322-344.

Edensor, T., (2000b). Walking in the British countryside: Reflexivity, embodied practices and ways to escape, Body \& Society, 6(3-4), pp. 81-106.

Easto, P., and Warburton, C. (2010). Adventure tourism in Scotland: Market analysis report for the tourism innovation group, Retrieved September 28, 2016, from the Wild Scotland website:

http://wild-scotland.org.uk/wp-content/uploads/2010/12/TIG-report.pdf

England, K. (1994). Getting personal: reflexivity, positionality and feminist research, The Professional Geographer, 46(1), 80-89.

Farkic, J. (2018). Outdoor guiding as hospitality work. Annals of Tourism Research, 73(C), 197-199.

Farkić, J., \& Taylor, S. (2019). Rethinking Tourist Wellbeing through the Concept of Slow Adventure. Sports, 7(8), 190.

Fox, K. M., Humberstone, B., \& Dubnewick, M. (2014). Cycling into sensoria: Embodiment, leisure, and tourism. Tourism Review International, 18(1), 71-85.

Gyimóthy, S. and Mykletun, R.J., (2004). Play in adventure tourism: The case of Arctic trekking. Annals of Tourism Research, 31(4), pp.855-878.

Hall, S. (1990). Cultural identity and diaspora, in J. Rutherford (ed.), Identity: Community, Culture, Difference, 2-27. London, England: Lawrence \& Wishart.

Hay, P. (2015). Outdoors. Not, Therefore, Indoors. In Experiencing the Outdoors. Enhancing Strategies for Wellbeing. Margaret Robertson, Ruth Lawrence and Gregory Heath (Eds.). Sense Publishers. 
Heidegger, M. (2010 [1972]). Being and time, Suny Press.

Heidegger, M. (1993). Building, Dwelling, Thinking, in M. Heidegger (ed.) Basic Writings, Revised and expanded edition, London: Routledge, 344-63.

Heimtun, B. (2016). Emotions and affects at work on Northern Lights tours. Hospitality \& Society, 6(3), 223-241.

Houge Mackenzie, S., \& Kerr, J. H. (2012). A (mis) guided adventure tourism experience: An autoethnographic analysis of mountaineering in Bolivia. Journal of Sport \& Tourism, 17(2), $125-144$.

Humberstone, B. (2015). Embodiment, Nature and Wellbeing: More Than the Senses?. In Experiencing the outdoors (pp. 61-72). Brill Sense.

Humberstone, B. (2013). Adventurous activities, embodiment and nature: Spiritual, sensual and sustainable? Embodying environmental justice. Motriz: Revista de Educação Física, 19(3), 565-571.

Ingold, T. (2008). Bindings against boundaries: entanglements of life in an open world. Environment and planning A, 40(8), 1796-1810.

Ingold, T. (2005). Epilogue: Towards a politics of dwelling, Conservation and Society, $3(2), 501$.

Ingold, T. (2000). The perception of the environment: essays on livelihood, dwelling and skill, Psychology Press.

Ingold, T. (1995). Building, dwelling, living: how animals and people make themselves at home in the world, Shifting contexts: Transformations in anthropological knowledge, 57-80.

Johnston, L. (2001). (Other) bodies and tourism studies. Annals of Tourism Research, 28(1), 180-201.

Kennedy, S., MacPhail, A., \& Varley, P. J. (2018). Expedition (auto) ethnography: an adventurer-researcher's journey. Journal of Adventure Education and Outdoor Learning, 115.

Kerr, J. H., \& Mackenzie, S. H. (2012). Multiple motives for participating in adventure sports. Psychology of Sport and Exercise, 13(5), 649-657.

Kobayashi, A. (1994). Coloring the field: Gender, "race" and the politics of fieldwork, The Professional Geographer, 46(1), pp. 73-80.

Koning, J. \& Ooi, C.S. (2013). Awkward encounters and ethnography, Qualitative Research in Organizations and Management: An International Journal, 8(1), 16-32.

Latour, B. (2005). Reassembling the social: An introduction to actor-network-theory, Oxford University Press.

Law, J. (2004). After method: Mess in Social Science Research. Routledge. 
Lewis, S.J. \& Russell, A.J. (2011). Being embedded: A way forward for ethnographic research, Ethnography, 12(3), 398-416.

Lee, J. \& Ingold, T. (2006). Fieldwork on foot: Perceiving, routing, socializing, Locating the field: Space, place and context in anthropology, 42, 67-85.

Lugosi, P. (2008). Hospitality spaces, hospitable moments: Consumer encounters and affective experiences in commercial settings, Journal of Foodservice, 19(2), pp. 139-149.

Macnaghten, P., \& Urry, J. (2000). Bodies in the woods. Body \& Society, 6(3-4), 166-182.

Marcus, G. E. (1998). Ethnography through thick and thin. Princeton University Press.

Markwell, K. (2001). 'An intimate rendezvous with nature'? Mediating the tourist-nature experience at three tourist sites in Borneo. Tourist Studies, 1(1), 39-57.

Merchant, S. (2011). Negotiating underwater space: the sensorium, the body and the practice of scuba-diving. Tourist Studies, 11(3), 215-234.

Moriarty, J. (2016). Autobiographical and researched experiences with academic writing: an analytical autoethnodrama. Writing in Practice, 2(1).

Nairn, K. (1999). Embodied fieldwork. Journal of geography, 98(6), 272-282.

Pickering, M. (2008). Research methods for cultural studies. Edinburgh University Press.

Pink, S. (2015). Doing sensory ethnography. Sage.

Pink, S. (2010). The future of sensory anthropology/the anthropology of the senses. Social Anthropology, 18(3), 331-333.

Polkinghorne, D.E. (2005). Language and meaning: Data collection in qualitative research, Journal of Counseling Psychology, 52(2), 137.

Punch, S. (2012). Hidden struggles of fieldwork: Exploring the role and use of field diaries, Emotion, Space and Society, 5(2), pp. 86-93.

Rantala, O. (2011) An ethnographic approach to nature-based tourism. Scandinavian Journal of Hospitality and Tourism, 11(2), pp. 150-165.

Rantala, O., Valtonen, A. \& Markuksela, V. (2011). Materializing tourist weather: ethnography on weather-wise wilderness guiding practices, Journal of Material Culture, 16(3), 285-300.

Scarles, C. (2009). Becoming tourist: Renegotiating the visual in the tourist experience. Environment and Planning D: Society and Space, 27(3), 465-488.

Sharpe, E. K. (2005). Delivering communitas: Wilderness adventure and the making of community. Journal of Leisure Research, 37(3), 255-280.

Still, J. (2011). Enlightenment hospitality: cannibals, harems and adoption. Voltaire foundation. 
Swain, M. (2004). (Dis)embodied experience and power, in J. a. G. Phillimore \& Lisa (eds.), Qualitative research in tourism: Ontologies, epistemologies, methodologies. New York: Routledge.

Thrift, N. (2008). Non-representational theory: Space, politics, affect. Routledge.

Thrift, N. (2004). Intensities of feeling: towards a spatial politics of affect, Geografiska Annaler, 86(1), 57-78.

Thrift, N. (1999). The place of complexity, Theory, Culture \& Society, 16(3), 31-69.

Thrift, N. (1997). The still point: resistance, expressive embodiment and dance, in Pile. S. and Keith, M., (eds.), Geographies of Resistance, London: Routledge, 124-51.

Trauer, B. (2006). Conceptualizing special interest tourism—-frameworks for analysis. Tourism Management, 27(2), 183-200.

Urry, J. (1990). The Tourist Gaze. London: Sage.

Varley, P., Farkic, J., \& Carnicelli, S. (2018). Hospitality in wild places. Hospitality \& Society, 8(2), 137-157.

Varley, P., \& Semple, T. (2015). Nordic slow adventure: Explorations in time and nature. Scandinavian Journal of Hospitality and Tourism, 15(1-2), 73-90.

Varley, P. J. (2011). Sea kayakers at the margins: the liminoid character of contemporary adventures. Leisure Studies, 30(1), 85-98.

Veijola, S., Molz, J. G., Pyyhtinen, O., Hockert, E., Grit, A., Molz, J. G., \& Höckert, E. (eds.) (2014). Disruptive tourism and its untidy guests: Alternative ontologies for future hospitalities. Springer.

Veijola, S., \& Jokinen, E. (1994). The body in tourism, Theory, Culture \& Society, 11(3), $125-151$

Walsh, K. (2009). Geographies of the heart in transnational spaces: love and the intimate lives of British migrants in Dubai, Mobilities, 4(3), 427-445.

Weiss, G. \& Haber, H.F. (1999). Perspectives on embodiment: The intersections of nature and culture. Psychology Press.

Widdowfield, R. (2000). The place of emotions in academic research, Area, 32(2), pp. 199208.

Wilson, E., \& Hollinshead, K. (2015). Qualitative tourism research: Opportunities in the emergent soft sciences. Annals of Tourism Research, 54, 30-47.

Wolf, E. (1982). Europe and the people without history. Berkeley and Los Angeles.

Cal./Londres: University of California Press. Chicago 
Wylie, J. (2005). A single day's walking: narrating self and landscape on the South West Coast Path, Transactions of the Institute of British Geographers, 30(2), 234-247. 